\title{
Isolation and selection of microorganisms in cocoa fermentation
}

\author{
Phong X. Huynh*, Thuy H. T. P. Ho, \& Thanh N. Nguyen
}

Biotechnology Research and Development Institute, Can Tho University, Can Tho, Vietnam

ARTICLE INFO
Research Paper
Received: November 22, 2018
Revised: February 08, 2019
Accepted: March 04, 2019
Keywords
Cocoa
Cocoa fermentation
Microflora of fermenting cocoa
Theobroma cacao

* Corresponding author

Huynh Xuan Phong Email: hxphong@ctu.edu.vn

\begin{abstract}
The objectives of this study were to investigate the change of microorganisms involved in cocoa (Theobroma cacao) fermentation and then to isolate, characterize and select the important microorganisms in cocoa fermentation. The results showed that microbial quantities continuously changed during cocoa fermentation and the highest quantity of dominant microorganisms at different stages of fermentation process as 8.03 $\log \mathrm{cfu} / \mathrm{g}$ of yeast, $6.34 \mathrm{log} \mathrm{cfu} / \mathrm{g}$ of mold, $7.77 \mathrm{log} \mathrm{cfu} / \mathrm{g}$ of lactic acid bacteria, $7.87 \mathrm{log} \mathrm{cfu} / \mathrm{g}$ of acetic acid bacteria, $7.25 \mathrm{log} \mathrm{cfu} / \mathrm{g}$ of Bacillus, and $10.93 \mathrm{log} \mathrm{cfu} / \mathrm{g}$ of the total aerobic bacteria. There were nine yeast isolates belonging 5 genera of Saccharomyces, Kluyveromyces, Brettanomyces, Candida and Cystofilobasidium; 9 mould isolates belonging to 2 genera of Rhizopus and Aspergillus; 11 acetic acid bacteria isolates belonging to Acetobacter; and 13 spore-forming bacterial isolates belonging to Bacillus isolates. Three isolates of yeast (CY-1a, CY-1b, $\mathrm{CY}-2 \mathrm{a})$ belonging to Kluyveromyces possessed the high fermentative capacity and 4 Acetobacter isolates (CAAB-1d, CAAB-1a, CAAB-1e and CAAB-2d) produced high amounts of acetic acid.
\end{abstract}

Cited as: Huynh, P. X., Ho. T. H. T. P., \& Nguyen, T. N. (2019). Isolation and selection of microorganisms in cocoa fermentation. The Journal of Agriculture and Development 18(4), 51-61. 


\title{
Phân lập và tuyển chọn vi sinh vật trong lên men cacao
}

\author{
Huỳnh Xuân Phong*, Hồ Huỳnh Thị Phương Thúy, \& Nguyễn Ngọc Thạnh \\ Viện Nghiên Cứu và Phát Triển Công Nghệ Sinh Học, Trường Đại Học Cần Thơ, Cần Thơ
}

\section{THÔNG TIN BÀI BÁO \\ Bài báo khoa học \\ Ngày nhận: 22/11/2018 \\ Ngày chỉnh sửa: 08/02/2019 \\ Ngày chấp nhận: 04/03/2019 \\ Từ khóa \\ Ca cao \\ Lên men ca cao \\ Theobroma cacao \\ Vi sinh lên men ca cao \\ *Tác giả liên hệ \\ Huỳnh Xuân Phong \\ Email: hxphong@ctu.edu.vn}

\section{TÓM TẮT}

Nghiên cứu này được thực hiện với mục tiêu xác định sự thay đổi của vi sinh vật trong quá trình lên men ca cao (Theobroma cacao) thông qua việc xác định, phân lập, nhận diện và tuyển chọn vi sinh vật hữu ích trong lên men ca cao. Kết quả cho thấy mật số vi sinh vật thay đổi trong quá trình lên men và chiếm ưu thế ở các giai đoạn lên men khác nhau, bao gồm nấm men $(8,03 \log \mathrm{cfu} / \mathrm{g})$, nấm mốc $(6,34 \log \mathrm{cfu} / \mathrm{g})$, vi khuẩn lactic $(7,77 \log \mathrm{cfu} / \mathrm{g})$, vi khuẩn acetic $(7,87 \log \mathrm{cfu} / \mathrm{g})$, vi khuẩn Bacillus $(7,25 \log \mathrm{cfu} / \mathrm{g})$ và tổng số vi khuẩn hiếu khí $(10,93 \log \mathrm{cfu} / \mathrm{g})$. Phân lập được 9 dòng nấm men thuộc 5 chi Saccharomyces, Kluyveromyces, Brettanomyces, Candida và Cystofilobasidium; 9 dòng nấm mốc thuộc hai chi Rhizopus và Aspergillus; 11 dòng vi khuẩn Acetobacter và 13 dòng vi khuẩn có khả năng hình thành bào tử thuộc chi Bacillus. Tuyển chọn được 3 dòng nấm men CY-1a, CY-1b, CY-2a thuộc chi Kluyveromyces có khả năng lên men mạnh và 4 dòng vi khuẩn Acetobacter CAAB-1d, CAAB-1a, CAAB-1e và CAAB-2d tạo ra lượng acid acetic cao.

\section{1. Đặt Vấn Đề}

Cây ca cao ( Theobroma cacao) có nguồn gốc từ các khu rừng nhiệt đới rậm rạp ở vùng Amazon (thuộc Nam Mỹ), thường phát triển ở những nơi có bóng râm và ẩm độ cao, nhưng các giống ca cao hoang dại cũng thấy xuất hiện từ Mexico đến Peru. Người thổ dân Mayas (thuộc Yacatan) và người Aztec (thuộc Mexico) đã trồng cây ca cao trong một thời gian dài trước khi được đưa đến Châu Âu (Wood \& Lass, 2001). Cây ca cao chỉ phát triển ở một số vùng địa lý giới hạn, ở khoảng vĩ độ 20 về cực Bắc và Nam tính từ đường xích đạo. Khoảng $70 \%$ diện tích trồng ca cao trên thế giới là ở khu vực Tây Phi với khoảng $72 \%$ tổng sản lượng, trong đó chủ yếu là các nước như Cote d'Ivoire, Ghana và Nigeria. Khu vực Châu Á Thái Bình Dương chiếm khoảng 15\%, khu vực Trung và Nam Mỹ chiếm khoảng 13\%. Tổng sản lượng niên vụ 2014 - 2015 đạt 4,24 triệu tấn (ICCO, 2017). Sản lượng ca cao trên thế giới gia tăng hàng năm bình quân khoảng 3,5\% trong năm thập kỷ gần đây và dự kiến trong những năm tới mức gia tăng này khoảng 1,5 - 3,5\%/năm (Anon, 1998).

Chất lượng hạt ca cao phụ thuộc vào nhiều điều kiện khác nhau như giống, mùa vụ, kỹ thuật trồng, thu hoạch, sơ chế, lên men, sấy. Trong đó, lên men là một công đoạn rất quan trọng để có thể sản xuất được hạt ca cao lên men đạt chất lượng cao. Chất nhầy bao quanh hạt ca cao là môi trường giàu dinh dưỡng cho sự phát triển cho vi sinh vật. Chất nhầy chiếm khoảng $82-87 \%$ nước, $10-15 \%$ đường, $2-3 \%$ pentose, $1-3 \%$ acid citric và $1-1,5 \%$ pectin. Ngoài ra còn có protein, amino acid, vitamin (nhiều nhất là vitamin $\mathrm{C}$ ) và chất khoáng. Ở các vùng khác nhau như Ivory Coast, Nigeria, Malaysia có sự khác biệt về hàm lượng nước, citrate, hemicellulose, lignin, peptin trong thịt quả hạt ca cao (Schwan \& Wheals, 2004).

Trong quá trình lên men, các vi sinh vật sẽ sử dụng phần thịt quả bao quanh hạt để lên men hình thành rượu, các loại acid hữu cơ và các phức hợp hữu cơ khác đồng thời sinh nhiệt. Nấm men có vai trò quan trọng trong quá trình lên men ở 24 - 30 giờ đầu và suy giảm dần. Nấm men chuyển 
hóa các chất nhầy có chứa đường của phần thịt quả thành ethanol $\left(\mathrm{C}_{2} \mathrm{H}_{5} \mathrm{OH}\right)$ và phóng thích khí carbonic $\left(\mathrm{CO}_{2}\right)$. Sự lên men rượu làm tăng nhiệt độ và vi khuẩn acid lactic bắt đầu phát triển. Tế bào của thịt quả ca cao bị phá vỡ làm nước thoát hết ra khỏi tế bào, oxy dễ dàng xâm nhập vào bên trong hạt và khi ây các vi khuẩn acetic bắt đầu hoạt động và phát triển mạnh, oxy hóa ethanol thành acid acetic $\left(\mathrm{CH}_{3} \mathrm{COOH}\right)$, làm tăng nhiệt độ khối hạt ca cao. Nhiệt và acid làm cho các phản ứng sinh hóa bên trong hạt bắt đầu xảy ra. Sau đó có thể xuất hiện một số bào tử và nấm mốc hình sợi trên bề mặt hạt do sự xâm nhiễm từ môi trường điều này có thể gây hư hỏng hoặc mùi hôi thối cho khối hạt. Vai trò sinh lý của vi sinh vật trong lên men hạt ca cao chưa được báo cáo đầy đủ, nhưng rõ ràng sự chuyển đổi về sinh hóa trong khối hạt có sự đóng góp của nấm men, các vi khuẩn lên men acid lactic và acid acetic. Trong đó, nấm men giữ vai trò quan trọng để chuyển hóa đường thành ethanol và sau đó vi khuẩn acetic chịu trách nhiệm chuyển hóa ethanol cũng như các hợp chất hữu cơ khác thành $\mathrm{CO}_{2}$ và nước góp phần làm giảm $\mathrm{pH}$ của sản phẩm ca cao lên men (Ardhana \& Fleet, 2003; Gálvez \& ctv., 2007; Sandhya \& ctv., 2016).

Mục tiêu của nghiên cứu nhằm xác định sự thay đổi vi sinh vật (vi sinh vật tổng số, nấm men, nấm mốc và vi khuẩn) trong quá trình lên men hạt ca cao cũng như phân lập và tuyển chọn các vi sinh vật hữu ích trong lên men ca cao. Kết quả nghiên cứu nhằm cung cấp thông tin khoa học về sự tham gia của vi sinh vật trong quá trình lên men ca cao cũng như định hướng ứng dụng các chủng vi sinh vật hữu ích trong lên men để cải tiến chất lượng hạt ca cao lên men.

\section{Vật Liệu và Phương Pháp Nghiên Cứu}

\subsection{Nguyên vật liệu và môi trường}

Mẫu ca cao được thu thập tại nông hộ Lâm Thế Cương và các nông hộ thuộc huyện Phong Điền, Thành phố Cần Thơ.

Các hóa chất sử dụng bao gồm: hóa chất nhuộm Gram (crystal violet, dung dịch iod, dung dịch khử màu (ethanol và aceton theo tỷ lệ $1: 1$ ), fushin), hóa chất nhuộm bào tử (dung dịch xanh methylen $1 \%$ và đỏ trung tính $0,5 \%$ ), thuốc thử catalase $\mathrm{H}_{2} \mathrm{O}_{2} 3 \%$, thuốc thử oxidase (Nam Khoa Biotek) và thuốc thử indole, hóa chất phân tích và nuôi cấy vi sinh vật $(\mathrm{NaOH} 0,1 \mathrm{~N}$, penicilline, oxytetracyline, peptone, phenol, agar, yeast ex- tract, D-glucose, $\mathrm{CaCO}_{3}, \mathrm{FeCl}_{3}$, ethanol $96 \%$, glycerol, natamycine). Các môi trường nuôi cấy vi sinh vật: Plate Count Agar (PCA), Oxytetracycline D-Glucose Yeast Extract Agar (OGYEA), Czapek-Dox Agar, MRS Agar, Nutrient Agar, YPGD (D-glucose $5 \mathrm{~g} / \mathrm{L}$, yeast extract $5 \mathrm{~g} / \mathrm{L}$, glycerol $5 \mathrm{~g} / \mathrm{L}$ và polypeptone $5 \mathrm{~g} / \mathrm{L}$, bổ sung ethanol $4 \%$ và $\mathrm{CaCO}_{3} 0,5 \%$ ).

\subsection{Khảo sát sự thay đổi mật số của vi $\sinh$ vật trong quá trình lên men ca cao}

Nhằm xác định sự thay đổi về mật số của vi sinh vật (vi sinh vật tổng số, nấm men, nấm mốc, vi khuẩn) trong quá trình lên men ca cao. Ca cao sau khi thu hoạch, tách hạt và được ủ trong điều kiện tự nhiên, mẫu được thu thập trong quá trình ủ tại các thời điểm $0,1,2,3,4,5,6$ và 7 ngày. Sau đó, vi sinh vật trong mẫu được phân tích trên môi trường chuyên biệt ở nồng độ pha loãng thích hợp, bao gồm tổng số vi khuẩn hiếu khí (PCA), nấm men (OGYEA), nấm mốc (CzapekDox Agar), vi khuẩn lactic (MRS Agar), vi khuẩn acetic (YPGD) và vi khuẩn Bacillus (Nutrient Agar). Thí nghiệm được lặp lại hai lần.

Đối với vi khuẩn lactic: đếm số khuẩn lạc phát triển trên môi trường thạch MRS sau khi ủ vi hiếu khí ở $30^{\circ} \mathrm{C}$ trong 48 giờ. Xác định số khuẩn lạc nghi ngờ là vi khuẩn lactic ở từng nồng độ pha loãng. Thực hiện nhuộm Gram, thử nghiệm catalase và thử nghiệm khả năng lên men acid lactic bằng thuốc thử Ufermen (Tran, 2008). Tiêu chuẩn xác định là vi khuẩn acid lactic: Gram dương, hình trực khuẩn, cầu khuẩn hoặc liên cầu khuẩn, catalase âm tính.

Đối với vi khuẩn acetic: đếm số khuẩn lạc phát triển trên môi trường thạch YPGD sau khi ủ hiếu khí ở nhiệt độ $37^{0} \mathrm{C}$ trong 48 giờ. Tiêu chuẩn xác định là vi khuẩn acetic: vi khuẩn acid acetic dễ dàng nhận thấy trên môi trường YPGD (do môi trường trường chứa $4 \%$ ethanol và $\left.0,5 \% \mathrm{CaCO}_{3}\right)$, sử dụng ethanol tạo ra acid acetic, acid hữu cơ tác dụng với $\mathrm{CaCO}_{3}$ tạo vùng sáng khuẩn lạc, Gram âm và catalase dương tính.

Đối với vi khuẩn Bacillus: Đếm số khuẩn lạc nghi ngờ trên môi trường thạch Nutrient agar sau khi ủ hiếu khí ở nhiệt độ $37^{0} \mathrm{C}$ trong 48 giờ. Xác định số khuẩn lạc nghi ngờ là vi khuẩn Bacillus ở từng nồng độ pha loãng. Sau đó, nhận diện vi khuẩn Bacillus thông qua việc xác định Gram và thử nghiệm catalase (Gram dương và catalase dương tính). 


\subsection{Phân lập vi sinh vật trong lên men ca cao}

Mục đích nhằm phân lập và định danh các dòng thuần nấm men, nấm mốc, vi khuẩn acetic và Bacillus hiện diện trong quá trình lên men ca cao. Thí nghiệm được thực hiện đồng thời với thí nghiệm trên, sử dụng môi trường chuyên biệt để nuôi cấy nấm men, nấm mốc, vi khuẩn acetic và Bacillus.

Tùy theo cách phát triển của từng nhóm vi sinh vật trên môi trường chuyên biệt mà khuẩn lạc có hình dạng, dạng bìa, độ nổi, màu sắc, kích thước khác nhau. Chọn các khuẩn lạc rời và cấy chuyền nhiều lần trên môi trường chuyên biệt để làm thuần. Quan sát tế bào vi sinh vật dưới kính hiển vi, nếu các tế bào vi sinh vật được quan sát đồng nhất thì có thể xác định đã thu được các dòng thuần chủng.

\section{4. Định danh sơ bộ vi sinh vật trong lên men ca cao}

Mục đích nhằm nhận diện và xác định các nhóm vi sinh vật khác nhau trong lên men ca cao để có định hướng nghiên cứu và ứng dụng các chủng vi sinh vật trong quá trình lên men ca cao. Các đặc điểm đặc trưng của từng nhóm vi sinh vật được dùng để phân loại, nấm men được phân loại dựa trên các đặc điểm hình thái, kích thước tế bào nấm men, hình dạng, số lượng bào tử trong túi bào tử, cách nảy chồi và các hình thức sinh sản (Luong, 2009; Kurtzman \& ctv., 2011); đối với nấm mốc, dựa trên các đặc điểm của sợi nấm (màu sắc, có vách ngăn hay không), các đặc điểm của cơ quan sinh sản (hình dạng, cách sắp xếp các bộ phận của cơ quan sinh sản và các đặc điểm về hình dạng, cấu tạo, cách sắp xếp của bào tử) (Hesseltine, 1991; Samson \& ctv., 2004); đối với vi khuẩn, dựa trên các đặc điểm về hình dạng tế bào, hình dạng khuẩn lạc, nhuộm Gram, thử nghiệm catalase, khả năng sinh khí khi lên men đường, $\mathrm{pH}$ phát triển, hình dạng và vị trí nội bào tử, hiếu khí hay yếm khí, môi trường phát triển (Holt \& ctv., 1994; Nguyen \& ctv., 2012).

\subsection{Tuyển chọn vi sinh vật hữu ích trong quá trình lên men ca cao}

Nhằm tuyển chọn các vi sinh vật có ảnh hưởng tích cực đến quá trình lên men hạt ca cao, các môi trường chuyên biệt nuôi cấy nấm men và vi khuẩn acetic được sử dụng. Dựa trên các thử nghiệm chuyên biệt để tuyển chọn các vi sinh vật tham gia trong quá trình lên men cao cao. Đối với nấm men, đánh giá khả năng lên men ethanol bằng cách lên men dung dịch đường glucose $2 \%(\mathrm{w} / \mathrm{v})$ trong ống nghiệm có chứa ống Durham, xác định chiều cao cột khí $\mathrm{CO}_{2}$ trong ống Durham (chiều cao $3 \mathrm{~cm}$ ) sau mỗi 2 giờ ở $30^{\circ} \mathrm{C}$. Đối với vi khuẩn acetic,đánh giá khả năng lên men tạo acid acetic bằng phương pháp khuếch tán trên giếng thạch và đo kích thước vòng phân giải $\mathrm{CaCO}_{3}$ trên môi trường YPGD có bổ sung $\mathrm{CaCO}_{3}$ sau 24 giờ nuôi cấy ở $30^{\circ} \mathrm{C}$. Thí nghiệm được lặp lại ba lần và nấm men Saccharomyces cerevisiae No. 2.1 (LU $1250, \mathrm{CY}-\mathrm{V})$ được sử dụng như đối chứng.

\subsection{Xử lý số liệu}

Số liệu được xử lý bằng phần mềm Microsoft Excel 2010 (Micrsoft Corporation, USA). Phần mềm Statgraphics Centurion XV (Manugistics Inc., USA) được sử dụng để phân tích phương sai và kiểm định $\mathrm{LSD}$ các trung bình nghiệm thức.

\section{Kết Quả và Thảo Luận}

\subsection{Sự thay đổi mật số vi sinh vật trong quá trình lên men ca cao}

Sự thay đổi mật số vi sinh vật trong quá trình lên men ở quy mô nông hộ (khối lượng hạt lên men là $64,24 \mathrm{~kg}$ thu từ $250 \mathrm{~kg}$ trái ca cao) được trình bày ở Hình 1. Kết quả cho thấy sự hiện diện của hệ vi sinh vật rất đa dạng và mật số vi sinh vật luôn thay đổi trong suốt quá trình lên men, điều này tương đồng với những công bố trước đây của Gálvez \& ctv. (2007), Ngo \& ctv. (2013), Miguel \& ctv. (2017). Thịt quả ca cao chứa hàm lượng đường cao và $\mathrm{pH}$ ban đầu thích hợp cho sự phát triển của nấm men. Ngoài ra, nấm men còn có thể sử dụng carbohydrate từ cơm hạt trong điều kiện hiếu khí hoặc ky khí. Mật số nấm men đạt giá trị cao nhất ở ngày thứ 2 sau ủ $(8,03 \log \mathrm{cfu} / \mathrm{g})$ và có khác biệt ý nghĩa về mặt thống kê mức $5 \%$ so với ở các ngày còn lại. Tương tự, Ardhana \& Fleet (2003) đã công bố trong lên men ca cao ở Indonesia nấm men hiện diện với mật số cao nhất $7-8 \log \mathrm{cfu} / \mathrm{g}$ trong suốt 24 - 36 giờ đầu lên men. Mật số này giảm nhanh ở ngày thứ $3(5,67 \log \mathrm{cfu} / \mathrm{g})$ và hầu như không thay đổi nhiều ở ngày thứ 4 và thứ 5 (duy trì ở $5,78 \log \mathrm{cfu} / \mathrm{g}$ ) và sau đó giảm mạnh (chỉ còn khoảng 4,0 log cfu/g), khác biệt ý nghĩa thống kê ở mức $5 \%$ vào ngày thứ 6 . Sự thay đổi mật số nấm men trong quá trình lên men là do 


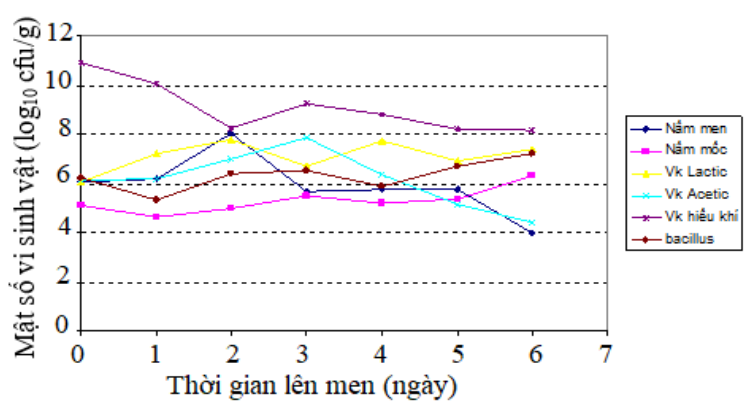

Hình 1. Sự thay đổi mật số vi sinh vật trong quá trình lên men ca cao.

trong điều kiện hiếu khí nấm men sinh sản gia tăng số lượng và trong điều kiện yếm khí nấm men chuyển hóa carbohydrate thành rượu và tỏa nhiệt làm ức chế trở lại hoạt động của nấm men. Đồng thời quá trình lên men còn làm $\mathrm{pH}$ khối ủ giảm và khối ủ trở nên thông thoáng hơn, do một số dòng nấm men có khả năng sinh ra enzyme phân giải pectin, phá vỡ lớp kết dính vách tế bào cơm hạt. Nhu mô của khối tế bào trong phần cơm gần hạt bị enzyme phân giải và tạo thành những khoảng không do sự xâm nhập của không khí. Do đó, điều kiện trong khối ủ không còn thích hợp cho sự phát triển của nấm men.

Vi khuẩn lactic (LAB) hiện diện trong khối ủ ngay từ khi bắt đầu đến khi kết thúc quá trình lên men và khi điều kiện thích hợp LAB gia tăng nhanh mật số. LAB đạt mật số cao nhất trong khoảng ngày thứ hai sau khi bắt đầu lên men $(7,77 \log \mathrm{cfu} / \mathrm{g})$. Kết quả này thấp hơn khi so với mật số LAB trong lên men ca cao ở Indonesia (Ardhana \& Fleet, 2003) đạt cao nhất ở 8 - 9 log cfu/g trong 36 giờ đầu lên men. Nhưng mật số này được duy trì trong thời gian rất ngắn, sau đó giảm xuống còn khoảng 6,71 log cfu/g vào ngày thứ 3 và tăng trở lại vào ngày thứ 4 (đạt 7,74 $\log \mathrm{cfu} / \mathrm{g}$ ) và ổn định đến cuối quá trình lên men (7,4 log cfu/g). Nhìn chung, trong quá trình lên men ca cao, mật số LAB thay dổi không có ý nghĩa về mặt thống kê mức $5 \%$ giữa các ngày lên men. Vi khuẩn lactic có thể tồn tại lâu và mật số cao trong suốt quá trình lên men là do khả năng tăng trưởng trong điều kiện ky khí tùy nghi và nguồn dinh dưỡng đa dạng, vi khuẩn lactic có thể sử dụng cả acid citric và acid malic. Điều này làm cho tính acid giảm và giá trị $\mathrm{pH}$ tăng. Tuy nhiên, LAB trong quá trình sinh trưởng tạo ra acid lactic, là một chất khó bay hơi, do đó có thể duy trì tính acid trong khối ủ giai đoạn cuối quá trình lên men.
Kết quả trên cho thấy có sự liên tiếp nhau chiếm ưu thế của các vi sinh vật trong suốt quá trình lên men ca cao. Khi điều kiện khối ủ trở nên thoáng khí hơn tạo điều kiện thích hợp cho sự phát triển của vi khuẩn acetic $(\mathrm{AAB})$. Mật số $\mathrm{AAB}$ đạt cao nhất vào khoảng ngày thứ $3(7,87$ $\log \mathrm{cfu} / \mathrm{g})$ trong quá trình lên men ca cao, tương tự với công bố của Vuong \& Ha (2006), mật số $\mathrm{AAB}$ cũng đạt cao nhất vào ngày thứ $3(7,0 \mathrm{log}$ $\mathrm{cfu} / \mathrm{g})$. Sau đó, $\mathrm{AAB}$ trong khối ủ giảm dần và đạt mức $4,44 \log \mathrm{cfu} / \mathrm{g}$ vào ngày thứ 6 . Vi khuẩn acetic oxy hóa rượu (sản phẩm của quá trình lên men kỵ khí của nấm men) thành acid acetic và có thể chuyển hóa tiếp acid acetic thành $\mathrm{CO}_{2}$ và $\mathrm{H}_{2} \mathrm{O}$. Phản ứng này tỏa nhiệt và đưa nhiệt độ khối ủ lên men lên cao.

Tổng số vi khuẩn hiếu khí trong khối ủ biến thiên theo từng ngày, mật số ban đầu cao nhất $(10,93 \log \mathrm{cfu} / \mathrm{g})$ và giảm mạnh, có khác biệt ý nghĩa về mặt thống kê mức $5 \%$ ở ngày thứ 2 , còn $8,28 \log \mathrm{cfu} / \mathrm{g}$. Đến ngày thứ 3 , mật số vi khuẩn hiếu khí gia tăng đến $9,25 \log \mathrm{cfu} / \mathrm{g}$ và lại giảm cho đến cuối quá trình lên men, ở mức 8,15 log $\mathrm{cfu} / \mathrm{g}$. Sự biến thiên này được giải thích bởi là do lúc đầu lượng thịt quả còn khá nhiều ngăn cản quá trình xâm nhập của oxy vào trong khối ủ nên các vi khuẩn hiếu khí khó phát triển, sau đó, nấm men đã phân hủy lớp cơm hạt tạo điều kiện thoáng khí hơn thuận lợi cho sự phát triển của vi khuẩn hiếu khí dẫn đến vi khuẩn hiếu khí gia tăng mật số và đạt mật số cao rồi giảm dần theo đường cong sinh trưởng.

Vào cuối giai đoạn lên men, mật số vi sinh vật có ích giảm dần, sự thông thoáng khí, $\mathrm{pH}$ và nhiệt độ khối ủ gia tăng, cùng với sự phát triển của chi Bacillus (đạt mật số cao nhất vào ngày thứ sáu $7,25 \log \mathrm{cfu} / \mathrm{g})$. Ngoài ra, điều kiện thông thoáng khí cũng thuận lợi cho sự phát triển của nấm mốc. Mật số nấm mốc từ $5,10 \mathrm{log} \mathrm{cfu} / \mathrm{g}$ ở ngày đầu tiên và giảm sau một ngày lên men $(4,64 \mathrm{log}$ cfu/g), sau đó gia tăng đến ngày thứ $3(5,52 \mathrm{log}$ cfu/g) và lại tiếp tục giảm khi nhiệt độ khối ủ quá cao và môi trường có $\mathrm{pH}$ quá thấp vào ngày thứ $4(5,22 \log \mathrm{cfu} / \mathrm{g})$ và gia tăng trở lại vào cuối giai đoạn lên men $(6,34 \log \mathrm{cfu} / \mathrm{g})$ khi điều kiện thuận lợi hơn.

\subsection{Phân lập và định định danh vi sinh vật tham gia trong quá trình lên men ca cao}

Trong quá trình lên men hạt ca cao, đã phân lập được 9 dòng nấm men, 9 dòng nấm mốc, 11 dòng vi khuẩn acetic và 13 dòng Bacillus. Dựa 
vào các đặc điểm về hình thái khuẩn lạc và tế bào cùng các phản ứng sinh hóa, các dòng vi sinh vật phân lập được phân loại và xếp vào từng nhóm, trong đó các dòng có đặc điểm giống nhau được xếp cùng một nhóm. Đối với nấm men, theo phân loại của Luong (2009) và Kurtzman \& ctv. (2011), các dòng phân lập được xếp thành 5 chi bao gồm Saccharomyces, Kluyveromyces, Candida, Brettanomyces và Cystofilobasidium, được mô tả chi tiết ở Bảng 1 và Hình 2. Dựa theo mô tả của Samson \& ctv. (2004), các dòng nấm mốc bao gồm 2 chi là Rhizopus và Aspergillus (Bảng 2 và Hình 3). Đối với vi khuẩn acetic, theo phân loại của Holt \& ctv. (1994), đã chọn được 2 nhóm khác nhau và đều thuộc chi Acetobacter (Bảng 3 và Hình 4). Theo phân loại vi khuẩn của và Nguyen \& ctv. (2012) đã chọn được 4 nhóm Bacillus khác nhau (Bảng 4 và Hình 5).

\subsection{Tuyển chọn vi sinh vật hữu ích trong lên men ca cao}

Nấm men và vi khuẩn acetic là 2 nhóm vi sinh vật có tác động tích cực đến chất lượng hạt ca cao (Schwan, 1998; Ho \& ctv., 2014), trong khi đó vi khuẩn lactic được chứng minh không có ảnh hưởngđến sự lên men (Ho \& ctv., 2015). Chính vì vậy, nghiên cứu chỉ tập trung khảo sát đặc tính lên men của nấm men và vi khuẩn acetic.

Hoạt lực lên men của nấm men được đánh giá thông qua lượng khí $\mathrm{CO}_{2}$ được sinh ra trong ống Durham khi lên men đường glucose trong ống nghiệm (Nguyen \& ctv., 2003). Chiều cao cột khí $\mathrm{CO}_{2}$ được đo ở các thời điểm khác nhau trong quá trình lên men của 9 dòng nấm men phân lập từ hạt ca cao và chủng Saccharomyces cerevisiae No. $2.1(\mathrm{CY}-\mathrm{V})$ làm đối chứng được trình bày ở Bảng 5. Kết quả cho thấy 3 dòng nấm men kí hiệu là CY-1a, CY-1b và CY-2a thuộc chi Kluyveromyces có xuất hiện khí trong ống Durham sớm nhất và tương đương nhau (16 giờ). Tuy nhiên, kết quả cho thấy khả năng lên men kém hơn so với dòng nấm men CY-V (12 giờ). Dòng nấm men CY-3a và $\mathrm{CY}-3 \mathrm{~b}$ hoàn toàn không lên men, đây có thể là Candida sp., nấm men này tồn tại rất lâu trong suốt quá trình lên men, dù không có khả năng lên men tạo ethanol nhưng lại có khả năng đồng hóa acid lactic (Gálvez \& ctv., 2007). Như vậy, qua thử nghiệm này đã sơ tuyển được 3 dòng nấm men có hoạt tính lên men cao là $\mathrm{CY}-1 \mathrm{a}, \mathrm{CY}-1 \mathrm{~b}$ và $\mathrm{CY}-2 \mathrm{a}$ với thời gian làm đầy cột khí $\mathrm{CO}_{2}$ trong 16 giờ lên men.

Vi khuẩn acetic sử dụng ethanol tạo ra acid acetic làm tan $\mathrm{CaCO}_{3}$ trên đĩa thạch và hình thành những vùng sáng xung quanh khuẩn lạc. Sau 24 giờ ủ, tất cả 11 dòng vi khuẩn acetic đều có khả săng sinh acid, trong đó dòng CAAB-1d có khả năng sinh acid cao nhất (tương ứng với đường kính vùng phân giải trung bình là 3,58 cm) (Hình 6). Các dòng CAAB-1a, CAAB-1e và CAAB-2d cũng tạo ra lượng acid acetic khá cao, đường kính vùng phân giải trong khoảng 3,03 3,17 cm (Hình 7).

(A)

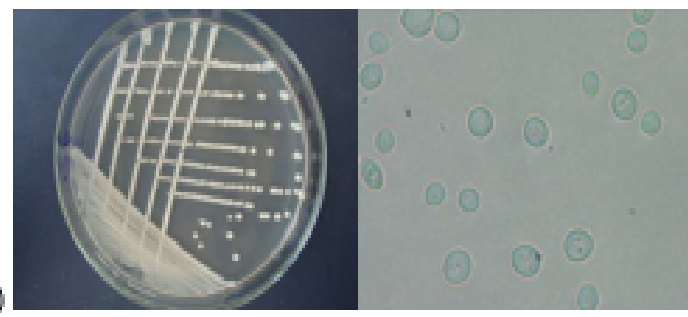

(B)

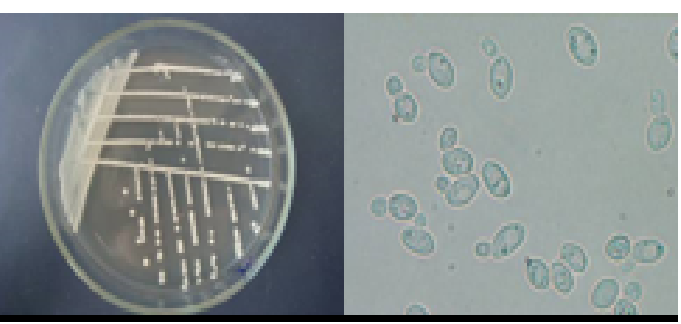

(C)

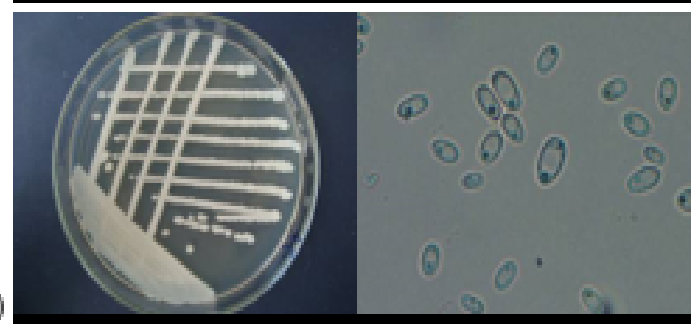

(D)

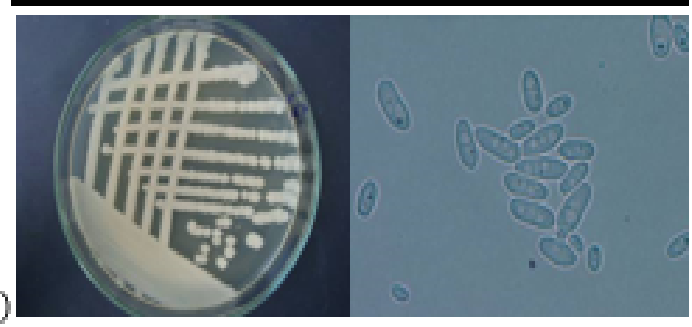

(E)

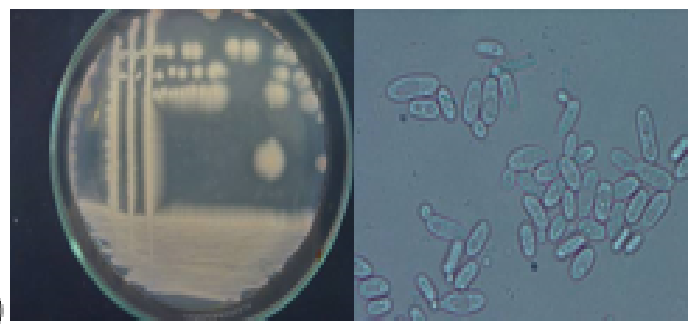

Hình 2. Khuẩn lạc và tế bào các dòng nấm men dưới kính hiển vi ở X100. Các dòng nấm men gồm $(\mathrm{A}) \mathrm{CY}$ 1, (B) CY-2, (C) CY-3, (D) CY-4 và (E) CY-5. 


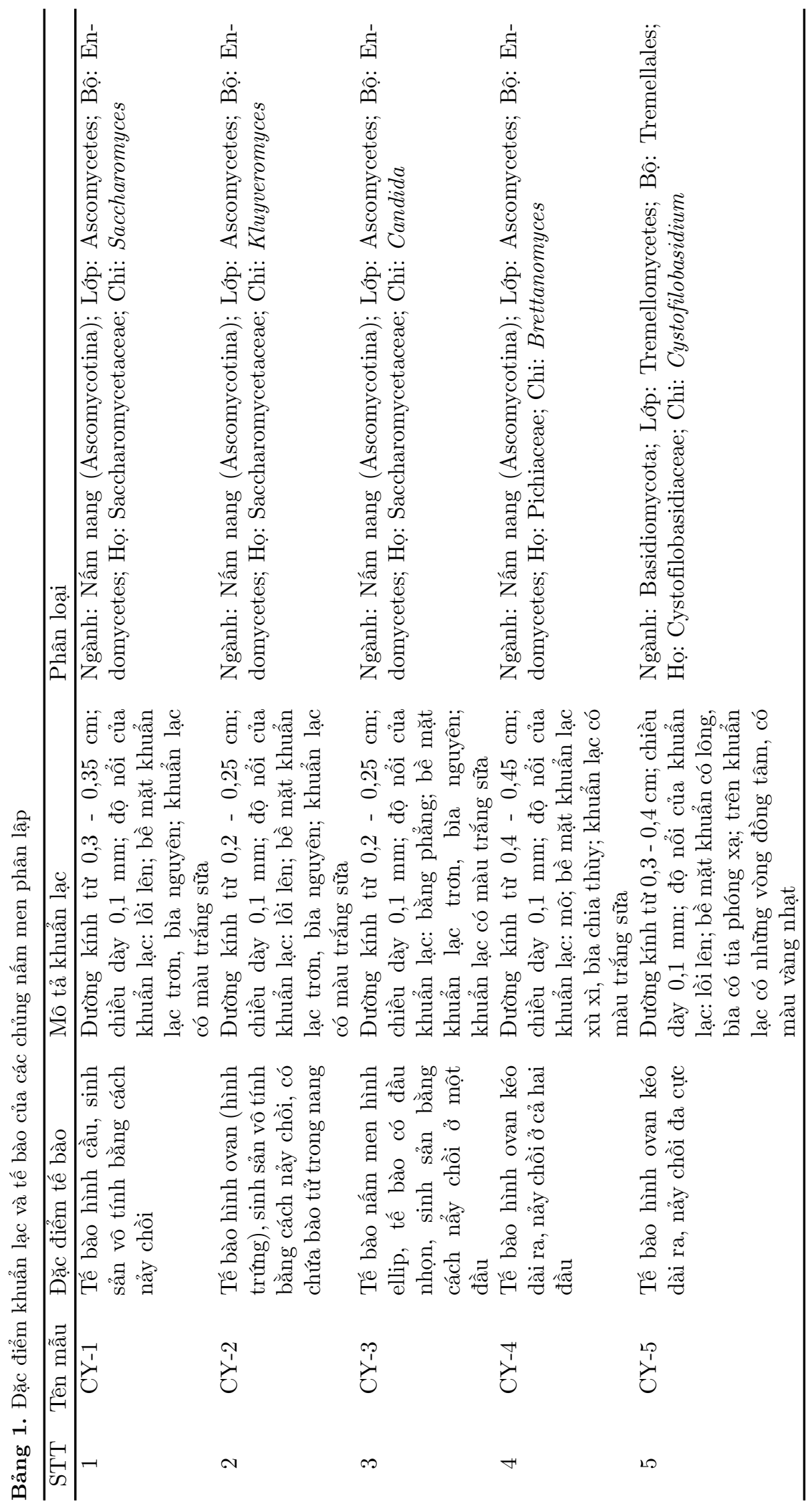




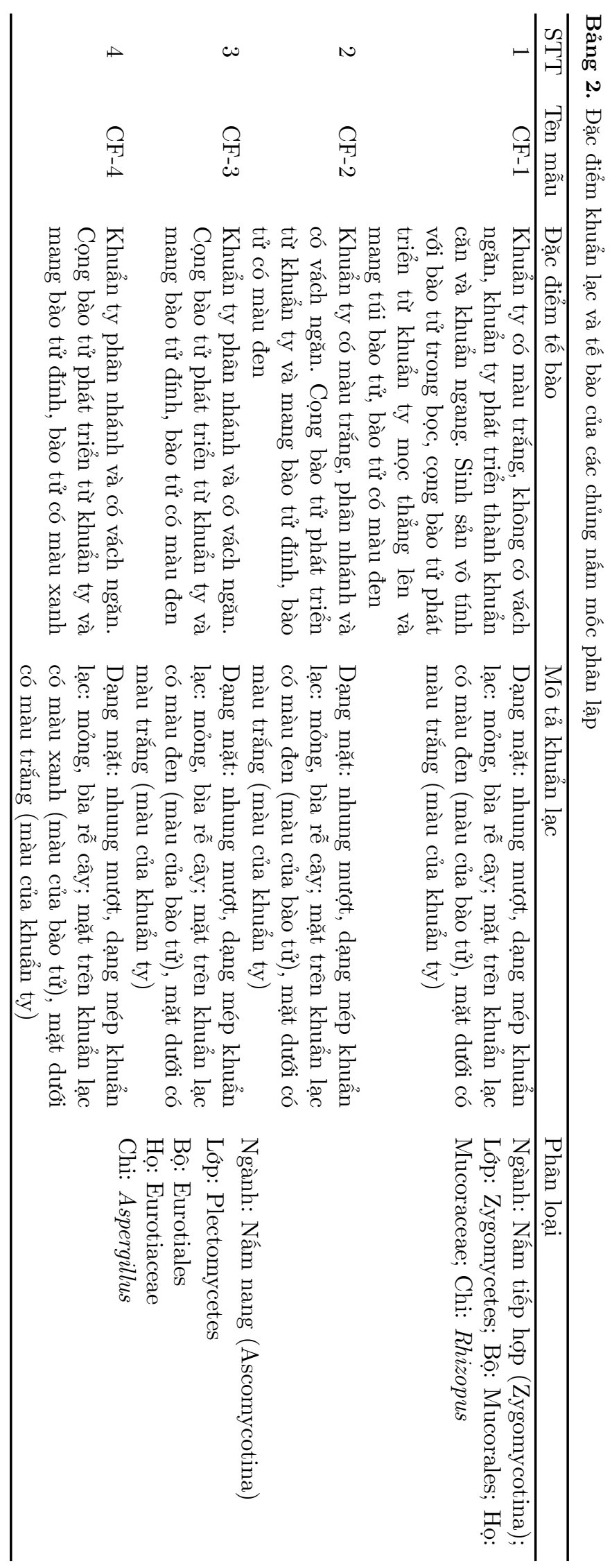


Bảng 3. Đặc điểm khuẩn lạc và tế bào của các chủng vi khuẩn acetic phân lập

\begin{tabular}{|c|c|c|c|c|}
\hline STT & Tên mẫu & Đặc điểm tế bào & Mô tả khuẩn lạc & Phân loại \\
\hline 1 & CAAB-1 & $\begin{array}{l}\text { Tế bào vi khuẩn } \\
\text { hình cầu; } 2,3 \text { tế } \\
\text { bào liên kêt với } \\
\text { nhau tạo thành } \\
\text { chuỗi ngắn }\end{array}$ & $\begin{array}{l}\text { Đường kính từ } 0,2-0,25 \\
\text { cm; chiều dày } 0,1-0,2 \text { mm; } \\
\text { giữa khuẩn bằng phẳng; bề } \\
\text { mặt khuẩn lạc trơn, bìa } \\
\text { nguyên; khuẩn lạc có màu } \\
\text { vàng }\end{array}$ & $\begin{array}{l}\text { Ngành: Proteobacteria } \\
\text { Lớp: Alpha Proteobacteria }\end{array}$ \\
\hline 2 & CAAB-2 & $\begin{array}{l}\text { Tế bào vi khuẩn } \\
\text { hình que, thường } \\
2,3 \text { tế bào liên } \\
\text { kết với nhau }\end{array}$ & $\begin{array}{l}\text { Đường kính từ } 0,15 \text { - } 0,2 \\
\text { cm; chiều dày } 0,1 \text { mm; giữa } \\
\text { khuẩn bằng phẳng hoặc hơi } \\
\text { mô lên; bìa nguyên; bề mặt } \\
\text { khuẩn lạc trơn, khuẩn lạc } \\
\text { có màu vàng }\end{array}$ & $\begin{array}{l}\text { Bộ: Rhodospirillales } \\
\text { Họ: Acetobacteraceae } \\
\text { Chi: Acetobacter }\end{array}$ \\
\hline
\end{tabular}

Bảng 4. Đặc điểm khuẩn lạc và tế bào của các chủng vi khuẩn Bacillus phân lập

\begin{tabular}{|c|c|c|c|c|}
\hline STT & Tên mẫu & Đặc điểm tế bào & Mô tả khuẩn lạc & Phân loại \\
\hline 1 & CB-1 & & $\begin{array}{l}\text { Đường kính từ } 0,65-0,75 \mathrm{~cm} \text {; } \\
\text { chiều dày } 0,15-0,25 \mathrm{~mm} \text {; bề mật } \\
\text { khuẩn lạc trơn phẳng, bìa rễ cây, } \\
\text { khuẩn lạc có màu trắng đục }\end{array}$ & \\
\hline 2 & CB-2 & & $\begin{array}{l}\text { Đường kính từ } 0,35-0,5 \mathrm{~cm} \text {; } \\
\text { chiều dày } 0,1-0,2 \mathrm{~mm} \text {; bề mặt } \\
\text { khuẩn lạc trơn phẳng; bìa chia } \\
\text { thùy, khuẩn lac có màu trắng đuc }\end{array}$ & Ngành: Firmicutes \\
\hline 3 & CB-3 & $\begin{array}{l}\text { Tế bào vi khuấn } \\
\text { hình que đơn hoặc } \\
\text { đôi }\end{array}$ & $\begin{array}{l}\text { Đường kính từ } 0,4-0,55 \mathrm{~cm} \text {; } \\
\text { chiều dày } 0,1 \text { mm; giữa khuẩn lạc } \\
\text { lõm xuống; bìa răng cưa; bề mặt } \\
\text { khuẩn xù xì, khuẩn lạc có màu } \\
\text { trắng đục }\end{array}$ & $\begin{array}{l}\text { Lớp: Bacilli } \\
\text { Bộ: Bacillales } \\
\text { Họ: Bacillaceae } \\
\text { Chi: Bacillus }\end{array}$ \\
\hline 4 & CB-4 & & $\begin{array}{l}\text { Đường kính từ } 0,4-0,55 \mathrm{~cm} \text {; } \\
\text { chiều dày } 0,1-0,2 \mathrm{~mm} \text {; giữa } \\
\text { khuẩn lạc lồi lên; bìa nguyên; bề } \\
\text { mặt khuẩn lạc trơn, khuẩn lạc có } \\
\text { màu trắng đục }\end{array}$ & \\
\hline
\end{tabular}

Bảng 5. Chiều cao cột khí $\mathrm{CO}_{2}(\mathrm{~cm})$ trong ống Durham

\begin{tabular}{ccccccccccc}
\hline \multirow{2}{*}{ Giờ } & \multicolumn{10}{c}{ Dòng nấm men } \\
\cline { 2 - 11 } & CY-1a & CY-1b & CY-2a & CY-2b & CY-3a & CY-3b & CY-4a & CY-4b & CY-5 & CY-V \\
\hline 4 & 0,17 & 0 & 0 & 0 & 0 & 0 & 0 & 0 & 0 & 0,1 \\
6 & 0,50 & 0,47 & 0,40 & 0,27 & 0 & 0 & 0,03 & 0 & 0 & 0,6 \\
8 & 1,07 & 1,10 & 0,97 & 0,77 & 0 & 0 & 0,10 & 0,10 & 0,10 & 1,5 \\
10 & 1,83 & 2,20 & 1,87 & 1,43 & 0 & 0 & 0,37 & 0,17 & 0,20 & 2,5 \\
12 & 2,53 & 2,63 & 2,43 & 2,03 & 0 & 0 & 0,50 & 0,30 & 0,27 & 3 \\
14 & 2,77 & 2,77 & 2,83 & 2,57 & 0 & 0 & 0,80 & 0,50 & 0,30 & $>3$ \\
16 & 3 & 3 & 3 & 2,77 & 0 & 0 & 1,03 & 0,67 & 0,37 & $>3$ \\
18 & $>3$ & $>3$ & $>3$ & 2,77 & 0 & 0 & 1,33 & 0,97 & 0,50 & $>3$ \\
20 & $>3$ & $>3$ & $>3$ & 2,83 & 0 & 0 & 1,83 & 1,20 & 0,57 & $>3$ \\
22 & $>3$ & $>3$ & $>3$ & 2,93 & 0 & 0 & 2,00 & 1,50 & 0,73 & $>3$ \\
24 & $>3$ & $>3$ & $>3$ & 3 & 0 & 0 & 2,03 & 1,73 & 0,73 & $>3$ \\
\hline
\end{tabular}




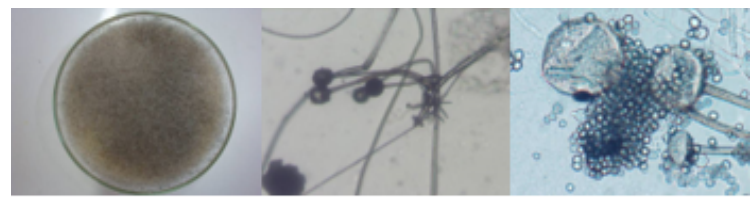

(A)

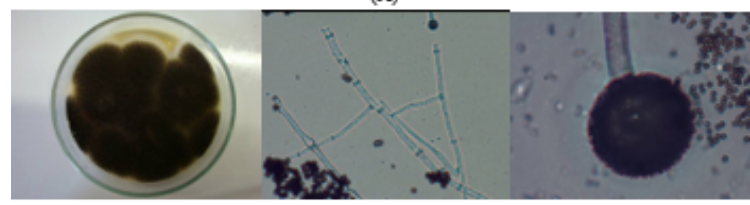

(B)

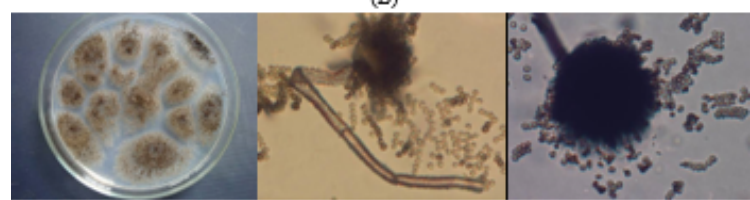

(C)

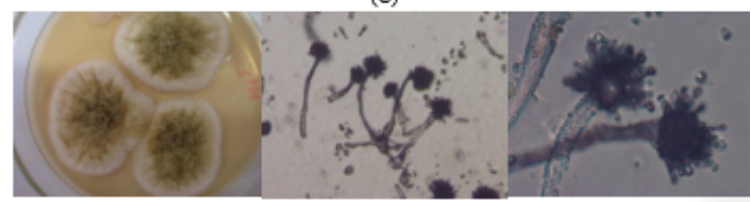

(D)

Hình 3. Khuẩn lạc, sợi nấm và bào tử dưới kính hiển vi ở X40. Các dòng nấm mốc gồm (A) CF-1, (B) $\mathrm{CF}-2$, (C) CF-3 và (D) CF-4.
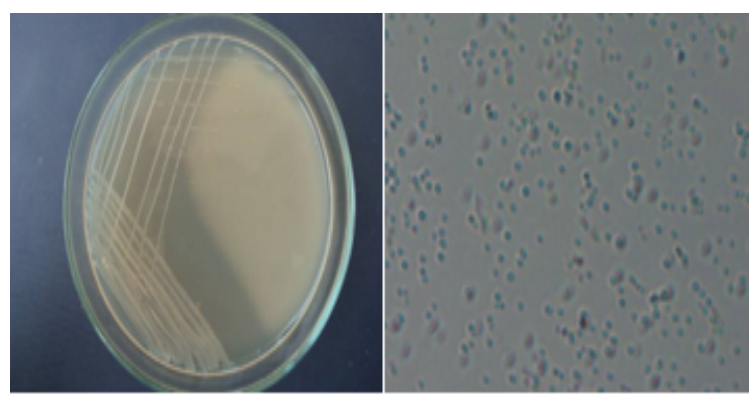

(A)
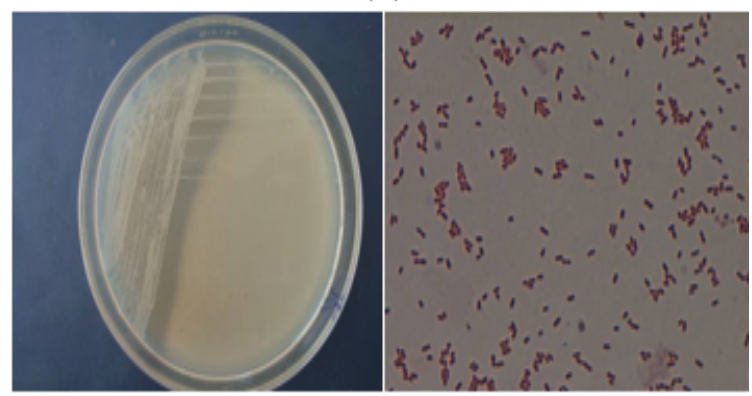

(B)

Hình 4. Khuẩn lạc và tế bào (nhuộm Gram) vi khuẩn acid acetic dưới kính hiển vi ở X100. Các dòng vi khuẩn acid acetic gồm $(\mathrm{A}) \mathrm{CAAB}-1$ và $(\mathrm{B}) \mathrm{CAAB}-2$.

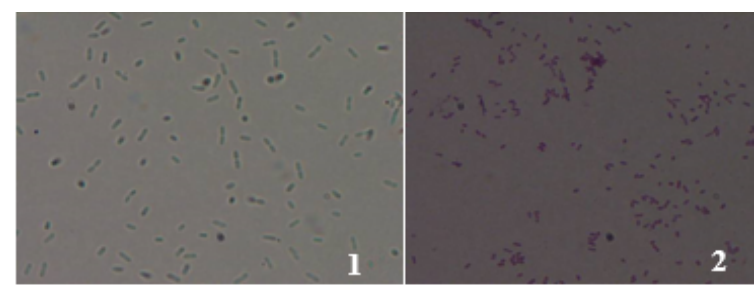

(A)

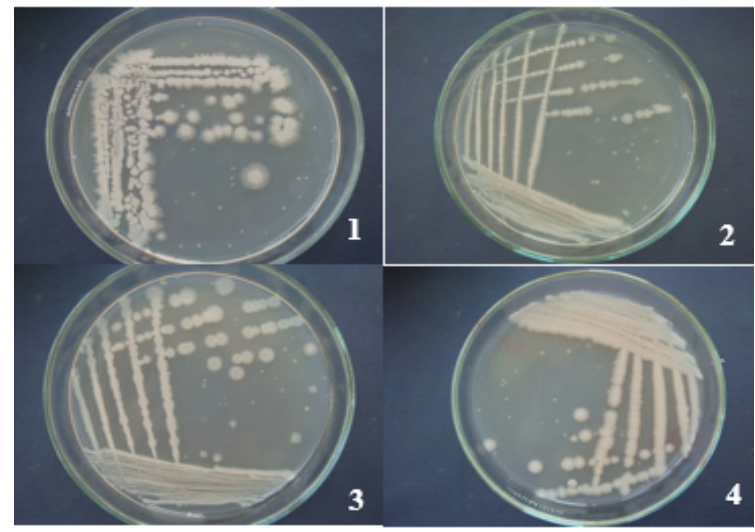

(B)

Hình 5. (A) Tế bào (1) và Gram (2) của các dòng Bacillus. (B) Khuẩn lạc của các dòng Bacillus gồm CB-1 (1), CB-2 CB-3 (3) và CB-4 (4).

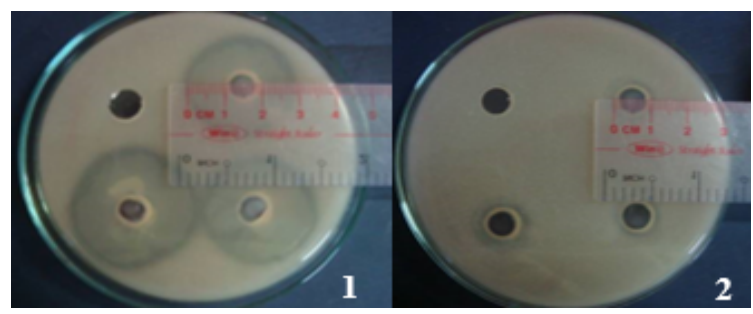

Hình 6. Đường kính vòng phân giải $\mathrm{CaCO}_{3}$ của CAAB-1d (1) và CAAB-2b (2).

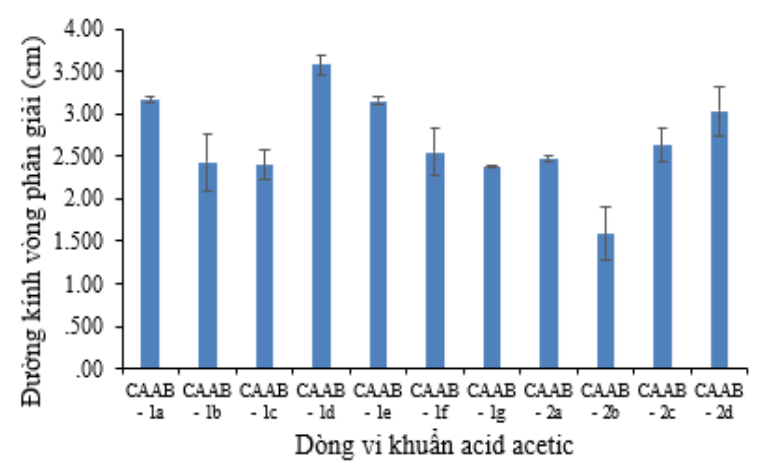

Hình 7. Khả năng phân giải $\mathrm{CaCO}_{3}$ của các dòng vi khuẩn acid acetic. 


\section{Kết Luận}

Mật số vi sinh vật tham gia trong lên men ca cao được xác định với mật số cao nhất lần lượt: nấm men $(8,03 \log \mathrm{cfu} / \mathrm{g})$, nấm mốc $(6,34 \mathrm{log}$ cfu/g), vi khuẩn lactic $(7,77 \log \mathrm{cfu} / \mathrm{g})$, vi khuẩn acetic $(7,87 \log \mathrm{cfu} / \mathrm{g})$, vi khuẩn Bacillus $(7,25$ $\log \mathrm{cfu} / \mathrm{g})$ và tổng số vi khuẩn hiếu khí $(10,93$ $\log \mathrm{cfu} / \mathrm{g})$. Phân lập được 42 dòng vi sinh vật bao gồm 9 dòng nấm men, 9 dòng nấm mốc, 11 dòng vi khuẩn acetic và 13 dòng Bacillus thuần chủng từ 2 mẻ ca cao lên men ở quy mô nông hộ tại thành phố Cần Thơ. Chín chủng nấm men thuộc 5 chi Saccharomyces, Kluyveromyces, Brettanomyces, Candida và Cystofilobasidium; 9 dòng nấm mốc thuộc hai chi Rhizopus và Aspergillus; 11 dòng vi khuẩn Acetobacter và 13 dòng vi khuẩn Bacillus. Tuyển chọn được 3 dòng nấm men CY-1a, CY-1b, CY-2a thuộc chi Kluyveromyces có khả năng lên men cao và 4 dòng vi khuẩn Acetobacter CAAB-1d, CAAB-1a, CAAB-1e và CAAB-2d tạo ra lượng acid acetic mạnh.

\section{Lời Cảm Ơn}

Nhóm tác giả xin chân thành cảm ơn sự hỗ trợ kinh phí từ đề tài nghiên cứu khoa học cấp cở sở Trường Đại học Cần Thơ.

\section{Tài Liệu Tham Khảo (References)}

Anon (1998). Review of annual forecast of world production and consumption. London, UK: International Cocoa Organization, ICC $/ 57 / 5$, ICCO.

Ardhana, M., \& Fleet, H. G. (2003). The microbial ecology of cocoa bean fermentations in Indonesia. International Journal of Food Microbiology 86, 87-99.

ICCO (International Cocoa Organization). (2017). ICCO Annual Report 2014/2015. Abidjan, Republic of Côte d'Ivoire: International Cocoa Organization.

Gálvez, L. S., Gérard, L., Jose, L. P., Michel, B., \& Joseph-Pierre, G. (2007). Study on the microflora and biochemistry of cocoa fermentation in the Dominican Republic. International Journal of Food Microbiology 114(1), 124-130.

Hesseltine, C. W. (1991). Zygomyces in food fermentations. Mycologist 5, 152-169.

Ho, V. T., Zhao, J., \& Fleet, G. (2015). The effect of lactic acid bacteria on cocoa bean fermentation. International Journal of Food Microbiology 205, 54-67.

Ho, V. T., Zhao, J., \& Fleet, G. (2014). Yeasts are essential for cocoa bean fermentation. International Journal of Food Microbiology 174, 72-87.
Holt, J. G., Krieg, N. R., Sneath, P. H. A., Stanley, J. T., \& Williams, S. T. (1994). Bergey's Manual of Determinative Bacteriology. ( $9^{\text {th }}$ ed.) Philadenphia, America: Lippincott Williams \& Wilkins.

Kurtzman, C. P., Fell, J. W., Boekhout, T., \& Robert, V. (2011). Methods for isolation, phenotypic characterization and maintenance of yeasts. In Kurtzman, C. P., Fell, J. W., \& Boekhout, T. (5 ${ }^{\text {th }}$ ed., 87-110). The Yeasts, a Taxonomic Study. San Diego, America: Elsevier B.V.

Luong, P. D. (2009). Yeast industry. Ha Noi, Vietnam: Science and Technics Publishing House.

Miguel, G. C. P. M., Reis, L. V. C., Efraim, P., Santos, C., Lima, N., \& Schwan, R. F. (2017). Cocoa fermentation: Microbial identification by MALDI-TOF MS, and sensory evaluation of produced chocolate. $L W T$ Food Science and Technology 77, 362-369.

Ngo, D. T. P., Nguyen, T. N., \& Huynh, P. X. (2013). Microflora composition and isolation of micro-organisms in cocoa fermentation. Can Tho University Journal of Science 25, 271-280.

Nguyen, L. D., Phan, H. T., \& Nguyen, T. A. (2003). Biotechnology laboratory manual- Part II Microbiological laboratory. Ho Chi Minh city, Vietnam: Viet Nam National University.

Nguyen, D. L., Nguyen, Q. D., \& Pham, T. V. (2012). Microbiology. Ha Noi, Vietnam: Vietnam Education Publishing House.

Samson, A. R., Hoekstra, S. E., \& Frisvad, C. J. (2004). Introduction to Food and Airbone Fungi. ( $6^{\text {th }}$ ed.). Virginia, America: ASM Press.

Sandhya, M. V. S., Yallappa, B. S., Varadaraj, M. C., Puranaika, J., Rao, J. L., Janardhan, P., \& Murthy, S. P. (2016). Inoculum of the starter consortia and interactive metabolic process in enhancing quality of cocoa bean (Theobroma cacao) fermentation. LWT - Food Science and Technology 65, 731-738.

Schwan, F. R. (1998). Cocoa fermentations conducted with a defined microbial cocktail inoculum. Applied and Environmental Microbiology 64(4), 1477-1483.

Schwan, F. R., \& Wheals, E. A. (2004). The microbiology of cocoa fermentation and its role in chocolate quality. Criticial reviews in Food Science and Nutrition 44(4), 205-221.

Tran, T. L. (2008). Microbiological analysis. Ha Noi, Vietnam: Vietnam Education Publishing House.

Vuong, T. T., \& Ha, T. T. (2006). Effects of fermented conditions on cocoa bean quality. Can Tho University Journal of Science 5, 149-157.

Wood, G. A. R., \& Lass R.A. (2001). Cocoa (4 $4^{\text {th }}$ ed.). New Jersey, America: Wiley-Blackwell. 